SRNL-STI-2012-00429

Rev. 0

\title{
ANALYSIS OF THE AXIAL GAP VS FIBERBOARD MOISTURE CONTENT IN A 9975 SHIPPING PACKAGE
}

\author{
W. L. Daugherty
}

Savannah River National Laboratory

Materials Science \& Technology

Publication Date: September 2013

Savannah River Nuclear Solutions

Savannah River Site

Aiken, SC 29808

This document was prepared in conjunction with work accomplished under

Contract No. DE-AC09-08SR22470 with the U.S. Department of Energy. 
SRNL-STI-2012-00429

Rev. 0

\section{DISCLAIMER}

This work was prepared under an agreement with and funded by the U.S. Government. Neither the U. S. Government or its employees, nor any of its contractors, subcontractors or their employees, makes any express or implied: 1 . warranty or assumes any legal liability for the accuracy, completeness, or for the use or results of such use of any information, product, or process disclosed; or 2. representation that such use or results of such use would not infringe privately owned rights; or 3. endorsement or recommendation of any specifically identified commercial product, process, or service. Any views and opinions of authors expressed in this work do not necessarily state or reflect those of the United States Government, or its contractors, or subcontractors. 


\title{
ANALYSIS OF THE AXIAL GAP VS FIBERBOARD MOISTURE CONTENT IN A 9975 SHIPPING PACKAGE
}

\author{
APPROVALS: \\ W. L. Daugherty \\ Date \\ Author, Materials Science and Technology \\ L. C. Olson \\ Date \\ Technical Review, Materials Science and Technology
}

K. A. Dunn

Date

Pu Surveillance Program Lead, Materials Science and Technology

G. T. Chandler

Date

Manager, Materials App \& Process Tech

E. R. Hackney

Date

NMM Engineering

REVIEWS:

D. R. Leduc

Date

Savannah River Packaging Technology 
SRNL-STI-2012-00429

Rev. 0

\section{Revision Log}

$\begin{array}{lll}\text { Document No. } & \text { SRNL-STI-2012-00429 Rev. No. } 0\end{array}$

Document Title Analysis of the Axial Gap vs Fiberboard Moisture Content in a 9975 Shipping Package

Rev. \# Page \# Description of Revision Date

$\begin{array}{lll}0 & \text { all Original document 9/30/2013 }\end{array}$ 
Rev. 0

\section{Analysis of the Axial Gap vs Fiberboard Moisture Content in a 9975 Shipping Package}

\section{Summary}

The fiberboard assembly within a 9975 shipping package contains a modest amount of moisture, which can migrate to the cooler regions of the package when an internal heat load is present. Typically, this leads to increased moisture levels in the bottom fiberboard layers, along with elevated chloride levels which can leach from the fiberboard. Concerns have been raised that this condition could lead to corrosion of the stainless steel drum. It has been postulated that checking the axial gap at the top of the package against the current 1 inch maximum criterion provides a sufficient indication regarding the integrity of the fiberboard and drum. This report estimates the increase in axial gap that might be expected for a given moisture increase in the bottom fiberboard layers, and the likelihood that the increase will create a nonconforming condition that will lead to identification of the moisture increase.

Using data relating the fiberboard moisture content with the degree of compaction under load, the present analysis indicates that the axial gap will increase by 0.282 inch as the bottom fiberboard layers approach the saturation point. This increase will cause approximately 58\% of packages with otherwise nominal package component dimensions to fail the axial gap criterion, based on a survey of axial gap values recorded in K-Area surveillance activities. As the moisture content increases above saturation, the predicted increase in axial gap jumps to 0.405 inch, which would result in $92 \%$ or more of all packages failing the axial gap criterion.

The data and analysis described in this report are specific to cane fiberboard. While it is expected that softwood fiberboard will behave similarly, such behavior has not yet been demonstrated.

\section{$\underline{\text { Introduction }}$}

Experience has shown that moisture present in the fiberboard overpack of the 9975 shipping package can migrate and concentrate when an internal heat load is present. This phenomenon can lead to elevated moisture levels in the bottom fiberboard layers, which can have several effects on the package:

- $\quad$ The lower fiberboard layers will compact under the load of package internal components.

- $\quad$ Regions of the fiberboard assembly that lose moisture will shrink.

- The axial gap at the top of the package (between the drum flange and upper fiberboard assembly, Figure 1) will increase.

- Chlorides can leach from the fiberboard, leading to pitting and/or stress corrosion cracking of the stainless steel drum.

Each of these effects is possible to some degree for any moisture redistribution. However, the likelihood of drum corrosion is small for modest increases in moisture level, and does not become significant until a liquid film forms on the drum surface. This would likely not occur until after the bottom fiberboard layers become saturated with water (at $28 \mathrm{wt} \%$ or $38 \%$ wood moisture equivalent). 
Rev. 0

When a 9975 package is certified, and before each use, the axial gap is verified to be less than 1 inch. This dimension is nominally 0.8 inch for a new package, but it is recognized that it can change over time [4]. It has been postulated that verifying that the axial gap meets the specified criterion provides sufficient warning to trigger an investigation before conditions degrade to the point of compromising package integrity [4].

Several tests were conducted to determine the impact of cane fiberboard moisture level on compaction under load. These tests were governed by Task Technical and Quality Assurance Plan SRNS-TR-2010-00044 [1]", which is part of the comprehensive 9975 package surveillance program [2]. Results are reported in Reference 3. This report provides an analysis based on the Reference 3 data to identify the extent that increasing moisture in the bottom fiberboard layers will be reflected in the axial gap measurement. Several components and regions of the package relevant to the analysis are identified in Figure 2.

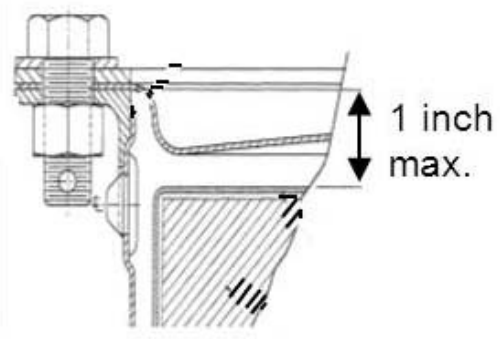

Figure 1. Sketch of axial gap in the 9975 package (from Reference 5)

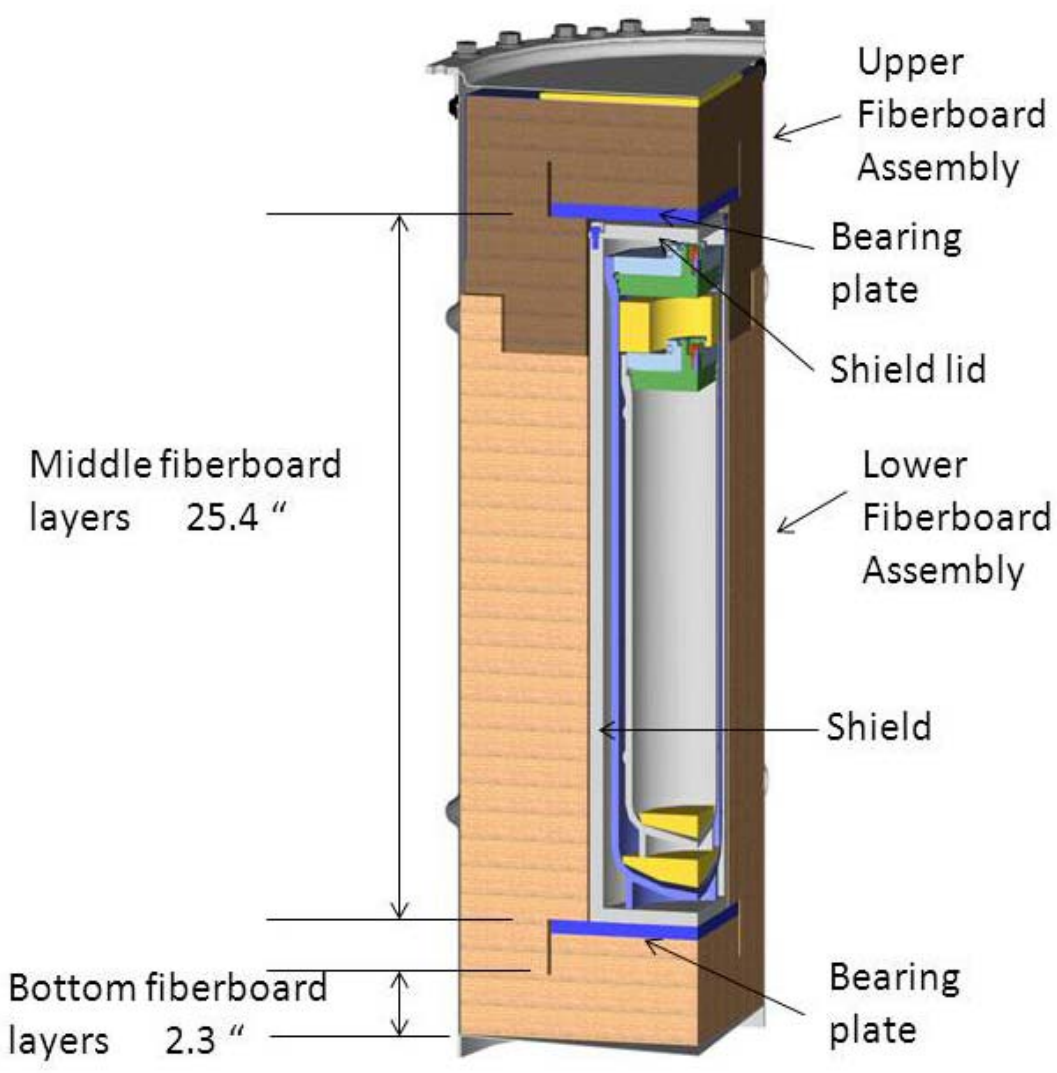

Figure 2. Cross section of 9975 package identifying fiberboard assemblies and other relevant features 
Rev. 0

\section{$\underline{\text { Data }}$}

Compaction data are presented in Reference 3 for several different loading scenarios. Three of these scenarios are directly applicable to storage, handling and/or shipping 9975 packages:

- Short-term post-cycle data measures the compaction following short-term application of a nominal load (to produce 2.7 psi stress), followed by application of a load to produce double the stress and its subsequent removal. This represents a single load cycle with a $1 \mathrm{~g}$ acceleration

- Dynamic samples experience a continuous static application of the nominal load, with weekly dynamic cycles produced by moving a cart containing the samples over a rough track on a weekly basis.

- Static samples duplicate the continuous static load of the dynamic samples, but without the weekly dynamic cycles.

Results of these tests are summarized in Figure 3. Given the overlap and similar trends for each scenario, they are grouped together for analysis. Two distinct regions are seen in Figure 3. At moisture levels below saturation (less than $~ 38 \% W M E$ or $\sim 28$ wt\%) compaction varies approximately linearly with moisture content for a given compressive stress. Above saturation, a constant compaction level of $13.7 \%$ conservatively bounds (under-predicts) the data.

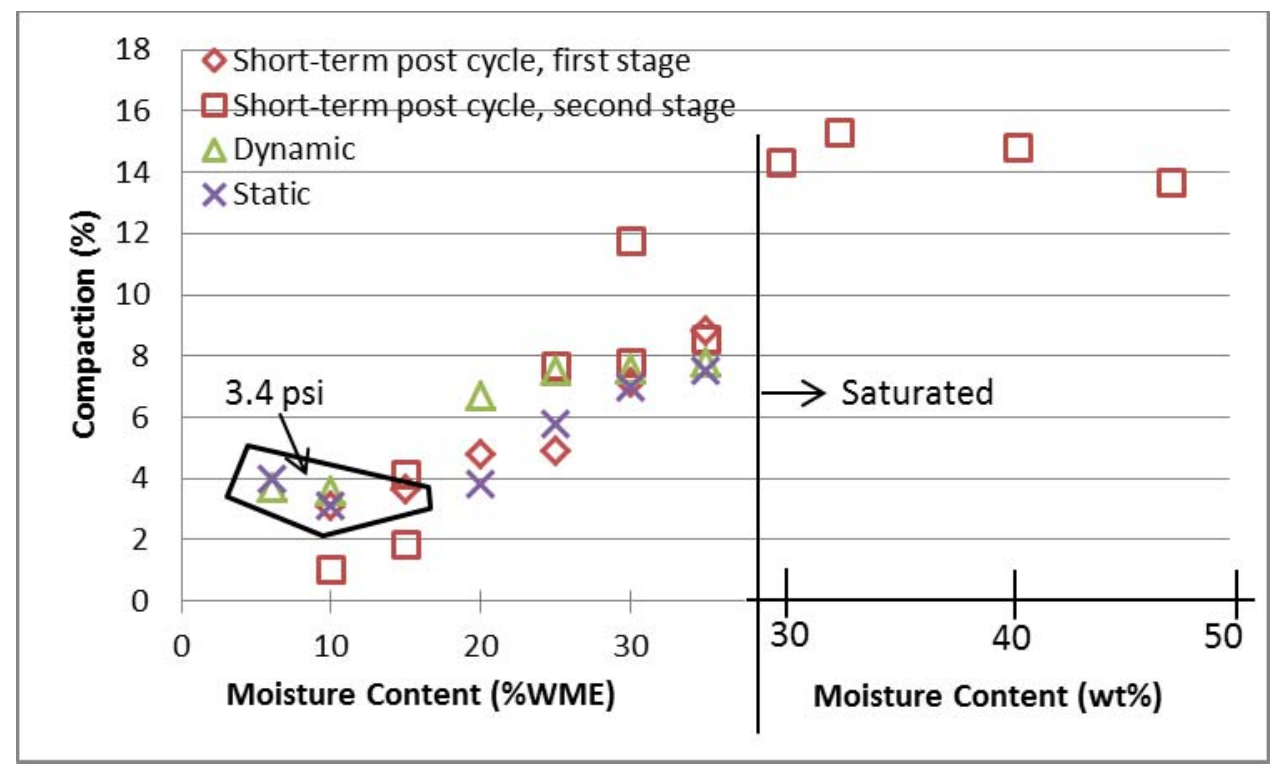

Figure 3. Summary of data reported in Reference 3. The enclosed data represent a compressive stress of 3.4 psi. The remaining data represent a compressive stress of 2.7 psi.

The enclosed data in Figure 3 identify the compaction measured under a nominal compressive stress of 3.4 psi. All other data correspond to a nominal stress of 2.7 psi. These values bound the range of peak fiberboard stress expected in a 9975 package. The second stage of short-term tests was conducted to accomplish two goals:

By including several data points at low moisture levels (15 \%WME or less) at the lower stress of 2.7 psi, it is easier to identify trends in behavior over the entire moisture range. 
Rev. 0

- $\quad$ Several data points at moisture levels above saturation (28 wt\%, or 38 \%WME) were included to identify whether fiberboard behavior changes in this extreme range.

The moisture content of samples is typically measured with a GE Protimeter Surveymaster moisture meter, which measures the electrical resistance of a sample and reports the result as \%wood moisture equivalent (\%WME). The meter has a linear response to varying moisture content up to the point of fiber saturation (28 wt\%, or 38 \%WME). Above this value, electrical resistance decreases rapidly as free moisture accumulates on the fiber surfaces, and the meter response becomes nonlinear. Therefore, moisture content above saturation is quantified as wt\% moisture, which is calculated by comparing the weight of a sample to its weight after drying in an oven. For cane fiberboard, these two scales are related as follows for values below saturation [6]:

$$
\mathrm{wt} \%=0.67 * \% \mathrm{WME}+2.6
$$

\section{$\underline{\text { Analysis }}$}

Analysis of the impact of fiberboard moisture on the axial gap consists of several elements, as follows.

- Define the degree of fiberboard compaction for a given moisture level under service load

- Characterize the drum bottom geometry to calculate the average compaction experienced as the fiberboard settles into the dished drum bottom

- For a given increase in the amount of water in the bottom fiberboard layers, calculate the moisture lost from the rest of the fiberboard assembly, and the impact of that moisture loss on the fiberboard assembly height

- Determine the combined impact of the above elements on the axial gap

- Characterize the range of axial gaps that exist for packages in service, to determine what portion of the package population would fail the axial gap criterion for a specific moisture level.

Each of these elements is discussed below.

Fiberboard Compaction vs Moisture:

At a modest moisture level, the fiberboard typically contacts the dished drum bottom in a narrow ring approximately $1.5-2$ inches wide. For a 1.5 inch width, the contact area is:

Contact area $-=\pi\left(18.1^{2}-15.1^{2}\right) / 4=78.2$ sq. in.

The combined weight of the lower bearing plate, lead shield, containment vessels and a typical 3013 payload is approximately 263 pounds. The fiberboard along the contact ring experiences a local stress of $263 / 78.2=3.4$ psi. This stress level was used in the Reference 3 study, and ignores the weight of the fiberboard itself - approximately 57 pounds for the lower assembly, and approximately 27 pounds for the upper assembly. As the fiberboard undergoes additional compaction and the contact ring widens, the local fiberboard stress level will decrease.

Directly under the lower bearing plate, the fiberboard experiences a fixed stress, defined by the 263 pounds of components bearing on it and the fixed contact area of the 11.2 inch diameter 
Rev. 0

bearing plate. In this area, the fiberboard stress is 263 / $98.5=2.7$ psi. (At this location, the weight of the fiberboard assemblies does not contribute to the local fiberboard stress.)

The Reference 3 tests were initially conducted with 3.4 psi stress on samples with $15 \% \mathrm{WME}$ moisture or less, and 2.7 psi stress on samples with higher stress levels. The second stage shortterm tests were performed with 2.7 psi stress on samples of all moisture levels. For this analysis, a stress level of 3.4 psi is assumed to establish the baseline compaction state of a typical package. An average compaction of 3.3\% is observed at $10 \%$ WME under 3.4 psi stress. From this initial condition, only tests with 2.7 psi stress are used to extrapolate subsequent behavior, to provide a consistent basis for curve-fitting and extrapolation. A stress level between 2.7 and 3.4 psi is expected to reasonably approximate the behavior of the bottom fiberboard layers within a 9975 package, and limiting consideration to the effects of the lower stress level (2.7 psi) is conservative with regards to predictions of the degree of fiberboard compaction.

Due to the slot in the fiberboard extending downward from the edge of the lower bearing plate, only the bottom 2.3 inches of fiberboard are active in carrying the load from the internal components to the outer region where the fiberboard contacts the drum bottom surface. Therefore, all compaction will be assumed to occur in the bottom 2.3 inches.

This analysis will assume initial uniform moisture content in a fiberboard assembly of 10 \%WME, which is typical of that seen in most packages. From Reference 3, the average compaction of samples under 3.4 psi stress at this moisture level is 3.3\%. Therefore, the bottom 2.3 inches are assumed to start with an initial compaction of 0.076 inch ( $3.3 \%$ x 2.3 ”).

A trendline might reasonably be fit to the Figure 3 data (below saturation) in the following ways:

- $\quad$ A linear best fit to all 2.7 psi data from all three types of test

- A linear best fit to all 2.7 psi data from the short-term tests only

- A linear lower bound fit to all 2.7 psi data from all three types of test

- A linear lower bound fit to all 2.7 psi data from the short-term tests only

The analysis described below has been performed using each of these 4 options. The lowest increase in axial gap is predicted with the third approach (linear lower bound fit to all 2.7 psi data from all three types of test). Since this is the most conservative, it is used in the analysis presented below. Predicted compaction based on the lower bound fit to all 2.7 psi data from all three types of test is tabulated in Table 1.

Table 1. Compaction predictions based on a lower bound fit to all 2.7 psi data

\begin{tabular}{|c|c|c|}
\hline \multicolumn{2}{|c|}{ Moisture Content } & \multirow{2}{*}{} \\
\cline { 1 - 2 } \%WME & $\mathrm{Wt} \%$ & \% Compaction \\
\hline 15 & 12.6 & 1.86 \\
\hline 20 & 16.0 & 3.27 \\
\hline 25 & 19.4 & 4.68 \\
\hline 30 & 22.7 & 6.09 \\
\hline 35 & 26.0 & 7.50 \\
\hline 38 & 28.1 & 8.35 \\
\hline
\end{tabular}


Rev. 0

\section{Drum Geometry:}

The drum bottom is dished by at least 0.37 inch, but not so much as to extend below the side lip, which is nominally 0.75 inch high (per drawing R-R2-F-0025). Two profiles have typically been used to accomplish this. In one profile, the entire drum bottom surface is a uniform curve, approximating a section of a spherical surface. The other profile includes an outer step, with a spherical surface section defining the region internal to the step. These two profiles are illustrated in Figure 4.

Six production drums have been measured to determine the depth to which the bottom is dished. The difference in drum bottom elevation was measured at the edge and in the center. Four such measurements were taken and averaged for each drum. One drum had a rounded bottom, and it was dished by approximately 0.34 inch. The other 5 drums were stepped, and the total amount of dishing (step plus center rounded region) ranged from 0.51 to 0.67 inch.

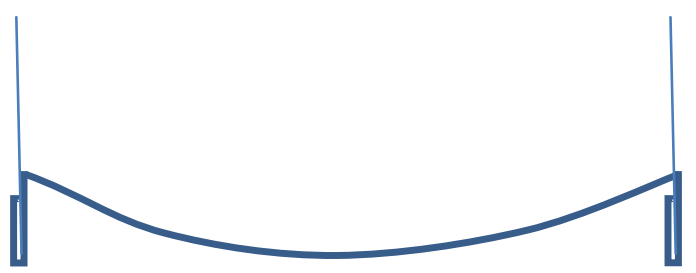

Rounded drum bottom

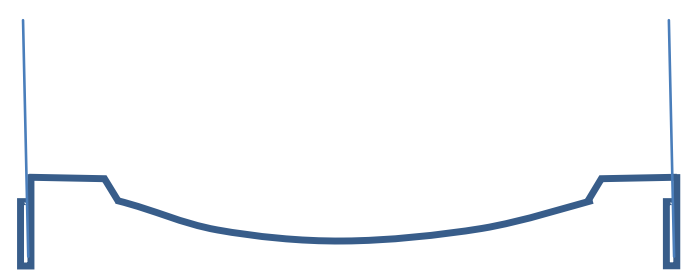

Stepped drum bottom

Figure 4. Sketch of drum bottom configurations (not to scale)

For the rounded drum bottom, it is observed that the outer edge of the drum bottom curves upward slightly before it starts to dish downward, due to the sharp bend where it contacts the drum sidewall. As a result, the outer $\sim 3 / 4$ inch is approximately flat. The area inboard of the outer $3 / 4$ inch has a radius of 8.30 inch. This idealized configuration is assumed for calculational purposes. If one also assumes this effective dished area is dished by the minimum specified 0.37 inch, then the dishing is defined by a spherical radius of 93.28 inch. For this idealized drum bottom shape, the fiberboard will compact by a set amount over the outer 0.75 inch, and by a decreasing amount over any additional contact area.

It can be shown that a total contact width of 2.12 inch, in which the fiberboard contacts the drum over 0.75 inch with uniform compaction, and the fiberboard contacts the drum over 1.37 inch with decreasing compaction, is consistent with the 0.076 inch compaction predicted for a moisture level of $10 \% \mathrm{WME}$, as follows. At the inside edge of this contact area, the drum bottom has dished to a depth of 0.112 inch. This produces 0.112 inch compaction over the outer 0.75 inch and an average of 0.056 inch over the next 1.37 inch, for an average compaction of 0.076 inch over the entire 2.12 inch. $((0.112 * 0.75+0.056 * 1.37) / 2.12=0.076)$ Note that the compaction test results are based on a stress level for an assumed contact width of 1.5 inch. As the fiberboard contact surface widens beyond 1.5 inch, the fiberboard stress will decrease and the amount of compaction required to support the load will decrease. Therefore, the actual contact width for a nominal $10 \% \mathrm{WME}$ fiberboard assembly would be expected to fall between 1.5 and 2.12 inch 
Rev. 0

Moisture Migration within the 9975 Package:

With an internal heat load in the package, several changes are expected to occur. The heat load will create a thermal gradient through the fiberboard, and the fiberboard moisture will redistribute preferentially to the cooler regions of the package. For typical package heat loads and service environments, the degree of moisture re-distribution is modest. However, for maximum heat loads and high external temperatures (especially as the local fiberboard temperature approaches the boiling point of water), a significant amount of moisture can re-distribute to the bottom of the package, up to and beyond the point of fiberboard saturation ( 38\%WME).

As the moisture content of the bottom layers increases, the compressive strength of those layers will decrease and the layers will compact further. This observed compaction is a net effect of two competing phenomena - the weakened fiberboard compacts under the load of the internal components, and the fiberboard fibers swell from the absorption of additional water. At the same time, the remainder of the fiberboard has lost moisture, and will shrink axially.

At least some of the fiberboard above the bearing plate in the upper assembly is also at elevated temperature, and moisture re-distribution from this area will also occur. The presence of the air shield could reduce the rate of moisture loss, but should not prevent it. However, the periodic measurements of the three life extension packages (laboratory tests to age entire 9975 packages at elevated temperature) do not show a strong indication of consistent shrinkage in the fiberboard above the bearing plate. Only the most extreme of these packages (LE2) shows a definite decrease in fiberboard thickness above the bearing plate - the other two packages show some scatter but no consistent direction of change (Figure 5). Therefore, it will be assumed that this region of fiberboard does not contribute significantly to changes in the axial gap for a package in service.

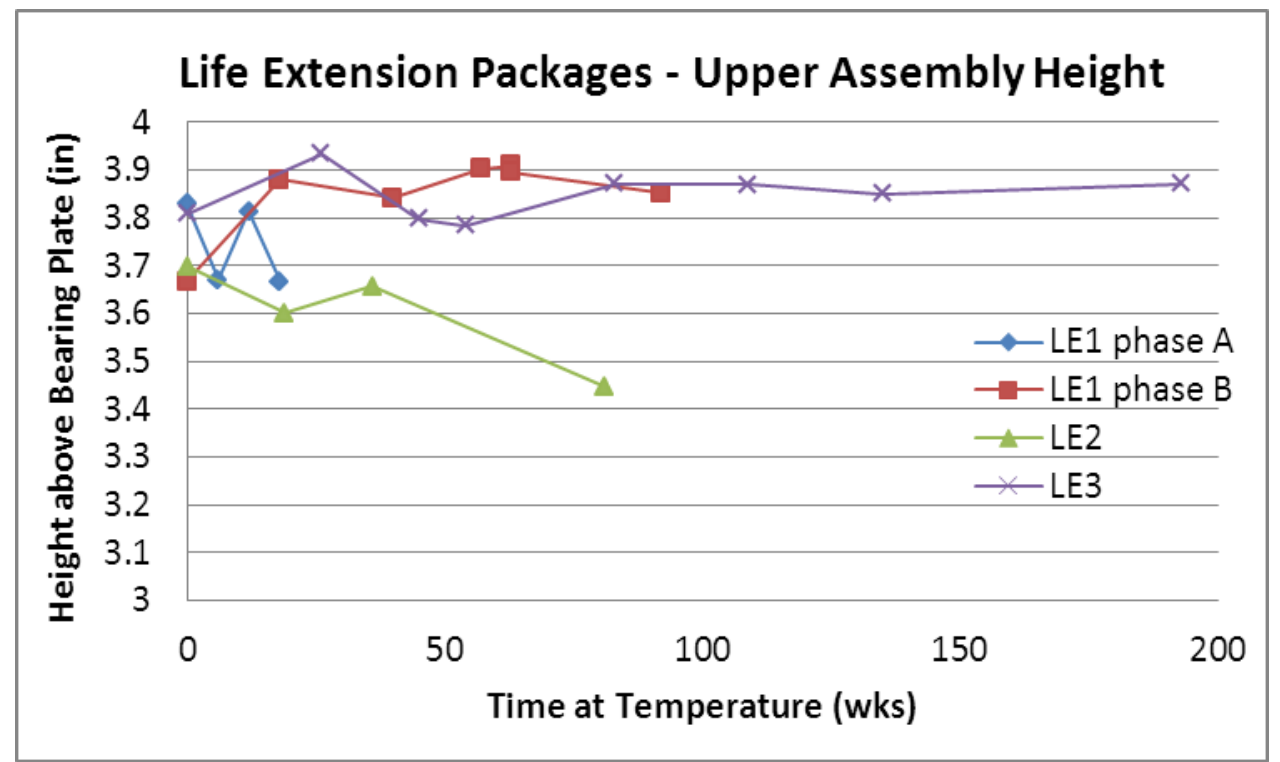

Figure 5. Variation in fiberboard height above the upper assembly bearing plate for the life extension test packages 
The middle region of the fiberboard assembly (which is typically the hottest) will lose moisture, and will shrink axially, as water migrates to the cooler regions of the package. This region consists of the fiberboard between the two bearing plates (over a nominal height of 25.4 inches, including portions of both the upper and lower fiberboard assemblies). The upper fiberboard assembly initially rests on the lower fiberboard assembly, with a nominal 0.25 inch gap between the shield lid and the upper assembly bearing plate. (With combination of tolerances, this gap can be as low as 0.05 inch.) As the middle fiberboard region shrinks axially, this will also contribute directly to the axial gap at the top of the package, until the upper assembly bearing plate is resting on the shield lid. After that, additional shrinkage will open a gap between the upper and lower fiberboard assemblies. Therefore, shrinkage of the middle fiberboard region can contribute at least 0.05 inch, and up to 0.25 inch for the nominal case, to the axial gap.

The contribution of shrinkage of the middle fiberboard region to the axial gap was limited to 0.25 inch for nominal packages, and 0.050 inch for packages with minimum tolerances of fiberboard and shield (minimum fiberboard height combined with maximum shield height). However, it is noted that as the fiberboard directly under the lower bearing plate compacts, this will allow the shield to shift downward as well. The amount of this movement will directly increase the extent to which shrinkage of the middle fiberboard region will contribute to the axial gap. This relative motion of the fiberboard under the bearing plate depends on a rotation of the lower fiberboard layers directly under the slot. Since the degree to which this hinge will be active has not been quantified, this benefit has not been included in the present analysis. However, it is noted that for the packages observed in which the bottom fiberboard layers exceeded saturation moisture content, the fiberboard was fully conformed to the drum bottom, suggesting that this hinge was active.

As the bottom fiberboard layers gain moisture, the middle fiberboard region will lose moisture, and shrink. For the bottom 2.3 inches of fiberboard to increase in moisture from 10 to 30 \%WME would require the migration of approximately $0.333 \mathrm{~kg}$ water, based on the following:

- $\quad$ The bottom 2.3 inches of fiberboard occupy a volume of 592 cubic inches.

- $\quad$ For a typical density of $0.28 \mathrm{~g} / \mathrm{cc}$, the bottom 2.3 inches of fiberboard weighs $2.715 \mathrm{~kg}$.

- $10 \% \mathrm{WME}$ corresponds to approximately $9.3 \mathrm{wt} \%$ water, and $30 \% \mathrm{WME}$ corresponds to approximately $22.7 \mathrm{wt} \%$ water

- If the bottom 2.3 inches of fiberboard weighs $2.715 \mathrm{~kg}$ at $10 \% \mathrm{WME}$, then the dry weight of that fiberboard is $2.484 \mathrm{~kg}$, and the weight at $22.7 \mathrm{wt} \%$ water is $3.048 \mathrm{~kg}$. This represents the addition of $0.333 \mathrm{~kg}$ water.

The additional $0.333 \mathrm{~kg}$ water in the bottom layers would migrate from the middle fiberboard layers, leaving them with less than $10 \% \mathrm{WME}$. The middle fiberboard layers (25.4 inches high, adjacent to the shield) have a volume of 5048 cubic inches, and weigh $23.16 \mathrm{~kg}$ (for a typical density of $0.28 \mathrm{~g} / \mathrm{cc}$ ). At $10 \% \mathrm{WME}$, this fiberboard has a dry weight of $21.191 \mathrm{~kg}$ and holds $1.971 \mathrm{~kg}$ water. With the loss of $0.333 \mathrm{~kg}$ water to the bottom layers, this region will hold 1.638 kg water, which corresponds to 7.73 wt\% water, or $7.65 \%$ WME.

In order to estimate the degree of axial shrinkage in the middle fiberboard layers, three fiberboard samples were measured at several equilibrium moisture levels ranging between 0 and 
Rev. 0

$\sim 10$ wt $\%$ water. These samples are non-degraded fiberboard used previously to correlate \%WME and wt\% moisture. Because fiberboard will exhibit a hysteresis effect depending on whether it has gained or lost moisture, these data were taken following moisture loss only, consistent with the moisture loss of the middle fiberboard layers. The data are presented in Table 2, and shown with linear fits in Figure 6.

Since slightly different curve fits are seen in Figure 6 for the MSC sample compared to the TC1R samples, using the lower slope for the TC1R samples will be conservative. Based on the Figure 6 curve fit, decreasing the moisture content of the middle fiberboard layers from 9.3 to 7.73 wt\% would decrease the height by $0.47 \%$, or 0.119 inch. If the gap between the shield lid and upper fiberboard assembly bearing plate is at least this large, then the entire 0.119 inch would add directly to the axial gap.

Table 2. Fiberboard height change as a function of moisture content

\begin{tabular}{|c|c|c|c|c|c|c|c|c|c|}
\hline $\begin{array}{l}\text { Sample } \\
\text { ID }\end{array}$ & $\begin{array}{c}\text { Weight } \\
\text { (g) }\end{array}$ & $\begin{array}{l}\text { Avg } \\
\text { Height } \\
\text { (inch) } \\
\end{array}$ & $\begin{array}{c}\text { Calculated } \\
\text { wt\% } \\
\text { Water } \\
\end{array}$ & $\begin{array}{c}\text { \% } \\
\text { Height } \\
\text { Change }\end{array}$ & $\begin{array}{l}\text { Sample } \\
\text { ID }\end{array}$ & $\begin{array}{l}\text { Weight } \\
\text { (g) }\end{array}$ & $\begin{array}{l}\text { Avg } \\
\text { Height } \\
\text { (inch) } \\
\end{array}$ & $\begin{array}{c}\text { Calculated } \\
\text { wt\% } \\
\text { Water } \\
\end{array}$ & $\begin{array}{c}\text { \% } \\
\text { Height } \\
\text { Change }\end{array}$ \\
\hline \multirow[t]{11}{*}{ MSC } & 29.814 & 1.972 & 8.557 & 3.030 & TC1R D & 47.935 & 3.451 & 7.925 & 2.404 \\
\hline & 29.736 & 1.968 & 8.273 & 2.821 & & 47.875 & 3.45 & 7.790 & 2.374 \\
\hline & 29.647 & 1.966 & 7.949 & 2.717 & & 47.736 & 3.452 & 7.477 & 2.433 \\
\hline & 29.168 & 1.951 & 6.204 & 1.933 & & 47.097 & 3.43 & 6.039 & 1.780 \\
\hline & 29.152 & 1.953 & 6.146 & 2.038 & & 47.083 & 3.428 & 6.007 & 1.721 \\
\hline & 29.068 & 1.952 & 5.840 & 1.985 & & 46.889 & 3.428 & 5.570 & 1.721 \\
\hline & 28.824 & 1.945 & 4.952 & 1.620 & & 46.533 & 3.415 & 4.769 & 1.335 \\
\hline & 28.804 & 1.944 & 4.879 & 1.567 & & 46.474 & 3.417 & 4.636 & 1.395 \\
\hline & 28.585 & 1.937 & 4.082 & 1.202 & & 46.158 & 3.405 & 3.924 & 1.039 \\
\hline & 27.592 & 1.915 & 0.466 & 0.052 & & 44.619 & 3.375 & 0.459 & 0.148 \\
\hline & 27.464 & 1.914 & 0.000 & 0.000 & & 44.415 & 3.37 & 0.000 & 0.000 \\
\hline \multirow[t]{10}{*}{ TC1R C } & 47.927 & 3.447 & 7.788 & 2.346 & & & & & \\
\hline & 47.976 & 3.449 & 7.899 & 2.405 & & & & & \\
\hline & 47.784 & 3.445 & 7.467 & 2.286 & & & & & \\
\hline & 47.06 & 3.424 & 5.838 & 1.663 & & & & & \\
\hline & 47.053 & 3.424 & 5.823 & 1.663 & & & & & \\
\hline & 47.022 & 3.427 & 5.753 & 1.752 & & & & & \\
\hline & 46.634 & 3.415 & 4.880 & 1.395 & & & & & \\
\hline & 46.517 & 3.412 & 4.617 & 1.306 & & & & & \\
\hline & 46.213 & 3.399 & 3.934 & 0.920 & & & & & \\
\hline & 44.464 & 3.368 & 0.000 & 0.000 & & & & & \\
\hline
\end{tabular}




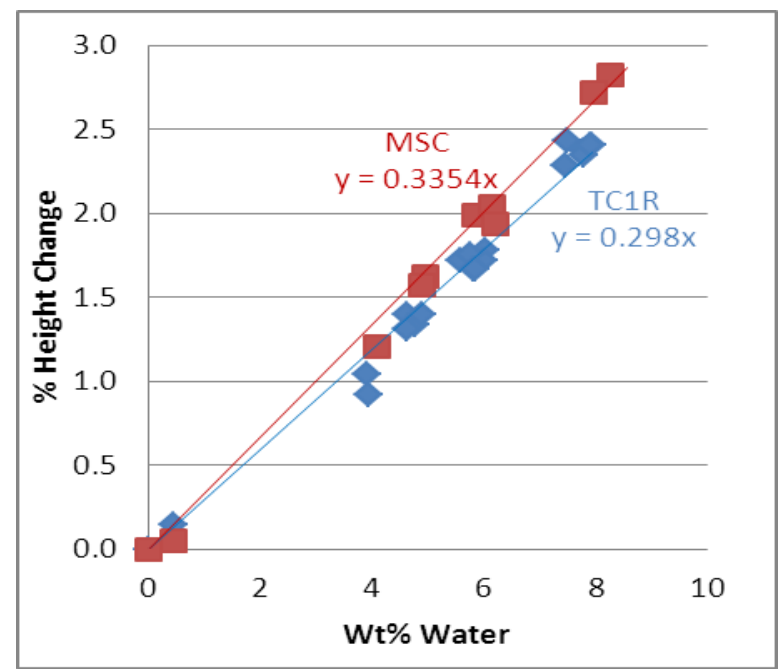

Figure 6. Fiberboard height change vs moisture level, with separate linear fit to MSC sample and TC1R samples

\section{Impact on Axial Gap:}

From the compaction testing, the fiberboard compresses 3.3\% under 3.4 psi stress at $10 \% \mathrm{WME}$. Therefore, the bottom 2.3 inches of fiberboard will compress by $(2.3$ inch x $0.033=)$ ) 0.076 inch, on average. As this occurs, the axial gap will increase by the same amount. It is assumed that this compaction occurs soon after initial assembly of the package, and represents the baseline package configuration.

As the moisture level in the bottom fiberboard layers increases from 10 to $30 \% \mathrm{WME}$ (and the contact area increases, reducing the local contact stress), Table 1 indicates a total compaction of 6.09\%. This correlates to 0.140 inch compaction, of which 0.076 inch is assumed to have occurred in the baseline configuration. An additional 0.064 inch compaction is realized from this moisture increase in the bottom fiberboard layers. The axial gap increases by the same amount (0.064 inch).

The middle fiberboard region shrinks axially by 0.119 inch as its moisture level decreases. For minimum tolerances of fiberboard and shield, only 0.050 inch of this shrinkage adds to the axial gap. More of this shrinkage contributes to the axial gap for dimensions closer to nominal values. If the initial gap between the upper bearing plate and shield lid is greater than 0.119 inch, then this entire amount will contribute to increasing the axial gap. The total effect on the axial gap therefore ranges from 0.114 inch for minimum tolerances to 0.183 inch for nominal tolerances.

The scenario described above for moisture in the bottom fiberboard layers increasing from 10 to $30 \%$ WME can be repeated for different final moisture levels. Table 3 summarizes the results for scenarios in which an initial $10 \% \mathrm{WME}$ moisture level increases to a range of values, up to saturation of the bottom layers (38\%WME). Figure 7 presents these results graphically. 
Rev. 0

Table 3. Predicted change in axial gap for a change in the moisture level of the bottom fiberboard layers from $10 \% \mathrm{WME}$ to the stated value.

\begin{tabular}{|c|c|c|}
\hline \multirow[b]{2}{*}{$\begin{array}{l}\text { New Moisture Level } \\
(\% W M E)\end{array}$} & \multicolumn{2}{|c|}{ Axial Gap Increase (inch) } \\
\hline & $\begin{array}{l}\text { Nominal } \\
\text { Tolerances }\end{array}$ & $\begin{array}{l}\text { Minimum } \\
\text { Tolerances }\end{array}$ \\
\hline $10 \% \mathrm{WME}$ & 0 & 0 \\
\hline $15 \% W M E$ & 0 & 0 \\
\hline $20 \% W M E$ & 0.059 & 0.049 \\
\hline $25 \% \mathrm{WME}$ & 0.121 & 0.082 \\
\hline $30 \% \mathrm{WME}$ & 0.183 & 0.114 \\
\hline $35 \% \mathrm{WME}$ & 0.245 & 0.146 \\
\hline $38 \% W M E$ & 0.282 & 0.166 \\
\hline $28.1 \mathrm{wt} \%$ & 0.405 & 0.288 \\
\hline $36.1 \mathrm{wt} \%$ & 0.476 & 0.288 \\
\hline
\end{tabular}

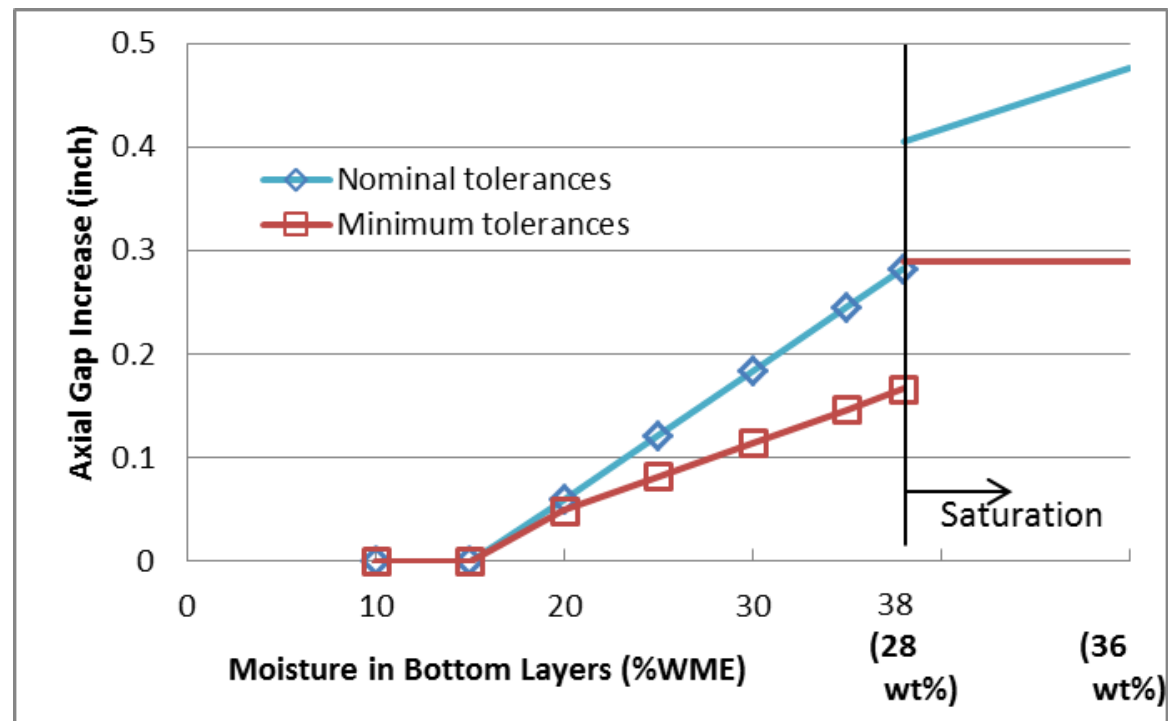

Figure 7. Predicted axial gap increase as a function of moisture level in the bottom fiberboard layers.

At concentrations below saturation ( 38 \%WME, or $28 \mathrm{wt} \%$ water), water is absorbed into the molecular structure of the cellulose. Once the saturation point is reached, any additional water will remain as free liquid, and will adsorb onto fiber surfaces and begin filling cell cavities and other void spaces. Because of this change in behavior, the data developed at moisture levels below the saturation point should not be extrapolated to predict the behavior of saturated fiberboard. For moisture levels above saturation, the data suggest a significant increase in fiberboard compaction, and a constant compression of $13.67 \%$ is conservatively assumed, as noted above. Figure 7 suggests an abrupt step change in compaction occurs upon reaching saturation. A period of transition would be expected, but the data suggest that such a transition occurs over a very small range of moisture increase. 
Rev. 0

Saturation is predicted to produce 0.314 inch compaction in the bottom 2.3 inches of fiberboard, or 0.238 inch compaction beyond the baseline condition. At $28.1 \mathrm{wt} \%$ moisture (just above saturation), the bottom layers will have gained $0.467 \mathrm{~kg}$ water and the middle fiberboard region has lost this amount, causing 0.167 inch axial shrinkage of the middle fiberboard region. The net increase in axial gap will be 0.405 inch for nominal tolerances, or 0.288 inch for minimum tolerances. This result is also indicated in Table 3 and Figure 7. As the moisture level continues to increase above saturation, additional compaction of the bottom fiberboard layers is not predicted, but additional shrinkage of the middle region will occur.

\section{Likelihood of Axial Gap Change Causing Package Rejection:}

The total axial gap increase resulting from increasing the moisture level of the bottom layers to $30 \% \mathrm{WME}$, due to compaction of the bottom fiberboard layers and shrinkage of the middle fiberboard region, is 0.183 inch. If a package had an initial axial gap of 0.817 inch or greater, an increase of 0.183 inch would be sufficient to fail the axial gap criterion. The axial gap has been recorded for 147 of the packages that underwent field surveillance in K Area (Figure 8). It is assumed that the field surveillance packages had axial gaps essentially unchanged from baseline, since they typically had relatively low heat loads and storage temperatures were relatively mild. The reasonableness of this assumption is seen by comparing the average measured axial gap ( 0.75 inch) to the nominal value ( 0.8 inch) Of these 147 packages, 40 packages, or $27 \%$, had an axial gap of 0.817 inch or greater. Similarly, $12 \%$ of the packages would fail the axial gap criterion in the event that minimum tolerances limit the axial gap increase to 0.114 inch. Similar percentages of packages to fail the axial gap criterion for a range of moisture content are shown in Figure 9. For nominal packages in which the bottom fiberboard layers exceed saturation, the likelihood of failing the axial gap criterion is very high (>92\%).

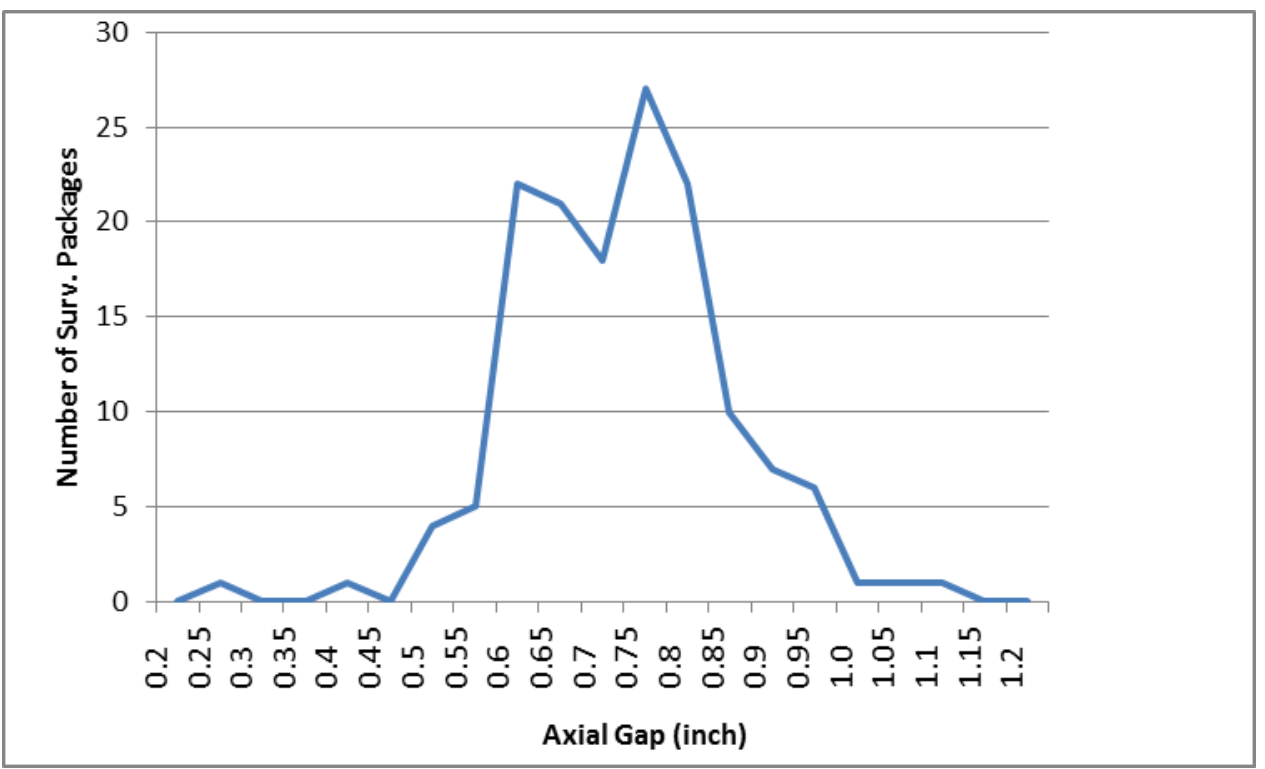

Figure 8. Summary of axial gap measurements from field surveillance activities. The number of packages having an axial gap within each interval is shown. Total number of packages is 147. 
Rev. 0

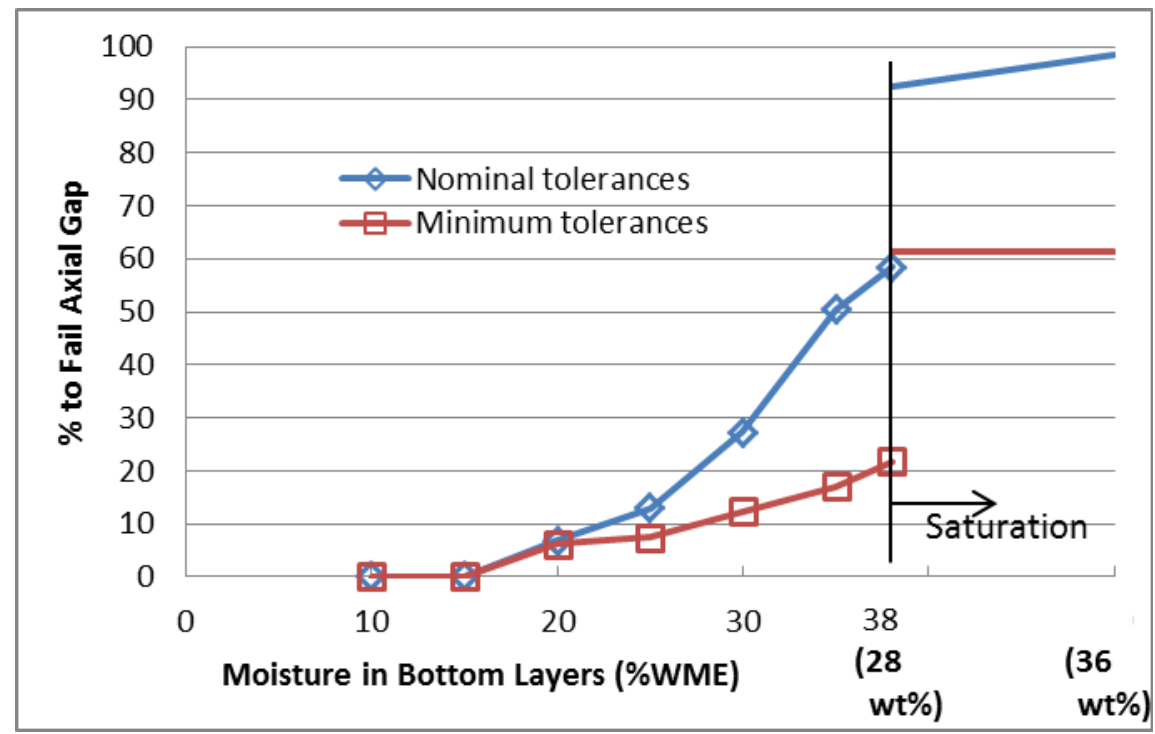

Figure 9. Estimated percentage of packages to fail the axial gap criterion as a function of moisture content in the bottom fiberboard layers.

All cases in which packages opened in $\mathrm{K}$ Area exceeded the 1 inch axial gap criterion were further examined to identify the cause of the axial gap. Most of these packages contained elevated moisture in the bottom fiberboard layers. Sufficient data were collected in some of these cases to characterize the approximate degree of compression of the bottom fiberboard layers, as indicated by the extent to which the fiberboard had conformed to the drum bottom.

- 9975-01818 and 9975-01819 both had high moisture levels (100\%WME, above saturation) in the bottom fiberboard layers. In both cases, the drum bottom was stepped, and the fiberboard had fully conformed to the drum bottom.

- 9975-02130 had a moisture content of 23 - 24 \%WME on the fiberboard bottom surface. The drum bottom was stepped, and the fiberboard had conformed to the outer step, but not the interior region.

- Packages 9975-01903 and 9975-02287 both had a moisture content of 18 \%WME in the bottom layers. Both packages had rounded drum bottoms, and in both cases, the fiberboard had conformed to the drum bottom over approximately 2 inches.

In addition, all three life extension packages had rounded drum bottoms, and the fiberboard fully conformed to the bottom. In each of these cases, the fiberboard moisture level on the bottom surface was $100 \% \mathrm{WME}$ at the time when full conformance to the drum bottom was also observed. This observation occurred after 57 weeks in test for LE1, after 36 weeks for LE2, and after 83 weeks for LE3. It is likely that this condition existed earlier in each package, but it was not a focus of examination at the time, and its presence or absence was not noted earlier.

\section{$\underline{\text { References }}$}

[1] SRNS-TR-2010-00044, “Task Technical and Quality Assurance Plan for Testing of Moisture Effects on Model 9975 Package (U)”, Rev 0, March 2010. 
Rev. 0

[2] WSRC-TR-2001-00286, “SRS Surveillance Program for Storage of Pu Material in KAMS”, Rev 6, October 2011.

[3] SRNL-STI-2012-00347, "Final Report for Moisture Effects on Compaction of Fiberboard in a 9975 Shipping Package”, T. M. Stefek, W. L. Daugherty and E. G. Estochen, March 2013.

[4] SRNL-L4400-2012-00010, "MS\&T Assessment of Potential for Corrosion of the Drum in the Model 9975 Radioactive Material Transportation Package”, T. M. Adams, April 10, 2012

[5] Drawing R-R2-F-0025, Rev. 5, “9975 Drum with Flange Closure Subassembly \& Details”

[6] SRNL-L7200-2008-00007, “Correlation between Cane Fiberboard Moisture Content and Relative Humidity”, W. L. Daugherty, December 10, 2008. 
Rev. 0

CC: J. S. Bellamy, 730-A

G. T. Chandler, 773-A

W. L. Daugherty, 773-A

K. A. Dunn, 773-41A

T. W. Griffin, 705-K

T. J. Grim, 105-K

E. R. Hackney, 705-K

D. R. Leduc, 730-A

J. W. McEvoy, 707-42B

L. C. Olson, 773-A

T. M. Stefek, 773-41A

K. E. Zeigler, 773-41A

Document Control 